\section{P113 CLINICAL USE OF ADAPTIVE SERVO-VENTILATION ACROSS THE UK: RESULTS OF A POSTAL SURVEY}

${ }^{1} \mathrm{CJ}$ Murphy, ${ }^{2} \mathrm{D}$ Gosh, ${ }^{1} \mathrm{~S}$ West. 'Newcastle Regional Sleep Centre, Freeman Hospital, Newcastle, UK; ${ }^{2}$ Sleep \& Non Invasive Ventilation Services, St. James's University Hospital, Leeds, UK

\subsection{6/thoraxjnl-2015-207770.250}

Introduction Adaptive Servo-Ventilation (ASV) is used to treat central sleep apnoea (CSA), but evidence for its use is limited. A large trial, SERVE-HF, randomised patients with CSA and left ventricular heart failure to ASV or control. Their results led to a field safety notice in May 2015, advising ASV is contraindicated in patients with symptomatic chronic heart failure and reduced ejection fraction. Sleep Centres therefore reviewed ASV in clinical practice; we sought information about ASV use in the UK.

Methods A survey was sent to 187 UK sleep centres, asking about the use of ASV.

Results Seventy-five surveys were returned (40\% response rate). ASV was not used in 53\% of centres.

Of the 47\% ( $\mathrm{n}=35)$ of sleep centres using ASV, the average number of patients on ASV per centre was 13 (range 1-69). For comparison, the average number on CPAP was 3368 (range 100-12000).

Of the 454 patients using ASV, the reasons are shown in Table 1.

\begin{tabular}{lll}
\multicolumn{2}{l}{ Abstract P113 Table 1} & \\
\hline $\mathbf{N}$ (total 454) & $\%$ & \\
\hline 149 & 33 & CSA with Cheyne Stokes Respiration (CSR) \\
126 & 28 & "Central" \\
61 & 13 & Mixed sleep apnoea \\
61 & 13 & Reasons not stated/unclear \\
23 & 5 & Complex sleep apnoea \\
22 & 5 & Due to opioid/narcotic use \\
12 & 3 & "Idiopathic"/other causes \\
\hline
\end{tabular}

Following the field safety notice, $66 \%$ of centres reviewed patients in clinic. Others contacted patients by phone $(45 \%)$ or in writing $(31 \%)$, or used a combination of these. Five centres did not contact their patients and five centres had to run between one and two additional clinics to review their ASV patients. Some repeated echocardiography.

Seventy-two (48\%) CSA-CSR patients were advised to stop using ASV. Fifteen chose to continue, 32 changed to CPAP/NIV, 14 stopped ASV, 11 were not specified.

Clinicians rated ASV as very useful (26\%), quite useful (23\%) and occasionally useful (49\%).

Conclusions There is a wide range of clinical ASV use in sleep centres across the UK; many do not use it. Apart from SERVE$\mathrm{HF}$, there are few randomised clinical trials to inform who would benefit from ASV. Use may be determined by case series, expert opinion and individual response. This highlights the need for further research in this area.

\section{P114 CAN A DEDICATED 'FAST TRACK' SLEEP SERVICE SUCCESSFULLY ESTABLISH VOCATIONAL DRIVERS ON CPAP WITHIN FOUR WEEKS OF REFERRAL?}

BAM Downie, G Olds, M Tomlinson, SD West. Newcastle Regional Sleep Service, Freeman Hospital, Newcastle Upon Tyne, UK

\subsection{6/thoraxjn|-2015-207770.251}

Introduction and objectives Sleepiness due to Obstructive Sleep Apnoea (OSA) can impair driving, and OSA has been implicated in road traffic accidents. DVLA guidelines state that those with "sleepiness sufficient to impair driving" should cease driving until they have been investigated and treated. This may have a significant effect on the ability of vocational drivers to earn a living. Fear of lengthy investigations and licence regulations may deter these patients from seeking treatment. We developed a dedicated service that aimed to diagnose OSA and successfully establish vocational drivers on CPAP within 4 weeks of referral. Methods The service was advertised to local GPs, encouraging identification of vocational drivers at point of referral. Patients were seen by a nurse specialist and underwent domiciliary sleep studies, returning the following day for results and CPAP therapy. Those who were not identified via GP referral were fasttracked from first clinic appointment. Compliance and Epworth Sleepiness Score (ESS) were evaluated after one week of treatment on CPAP, or as soon as the patient could attend thereafter. Results Between September 2014 and July 2015, 29 drivers were referred; one failed to attend. Fifteen held a type 1 drivers' licence and 13 a type 2 licence. At presentation, the mean age was 48 years (range 25-61), mean BMI was 34 (27-51) and mean ESS was $10(0-21)$. Sleep studies showed a mean ODI of 30 (0-93), with moderate or severe OSA in 18 (64\%). Twenty two patients were commenced on CPAP (79\%). Seventeen patients attended for review on CPAP, a mean of 16 days after initiation. Mean ESS was 5.4 and mean CPAP usage was $5.3 \mathrm{~h} /$ night. Of these, six people were reviewed between six and eight days after CPAP initiation; their mean compliance was $6.2 \mathrm{~h} /$ night (4.1-8.3). Mean time from referral (or first clinic visit) to review on CPAP was 33 days.

Conclusion A fast track service is practical and effective at diagnosing OSA and establishing vocational drivers on CPAP. There were some delays due to patient non-attendance or re-scheduling. It is vital that GPs are aware of the service and refer patients as vocational drivers.

\section{P115 OUTCOMES OF SLEEP STUDIES AND TARGETED THERAPIES IN PATIENTS WITH MYOTONIC DYSTROPHY: A COHORT STUDY}

SD West, KN Anderson, J Hughes, A Atalaia, SV Baudouin, H Lochmuller. Newcastle Upon Tyne Hospitals NHS Trust, Newcastle, UK

\subsection{6/thoraxjnl-2015-207770.252}

Patients with myotonic dystrophy (DM) have complex respiratory and neurological disease. Sleepiness is common. We describe a prospective cohort study of patients with DM and response to sleep treatments. 